Open Access

\title{
Error correction and repair moves in synchronous learning activities
}

Jorge Eduardo Pineda Hoyos ${ }^{1,2}$

Correspondence: eduardo.pineda@ udea.edu.co; jpinedah@uoc.edu ${ }^{1}$ Universidad de Antioquia, Medellín, Colombia

${ }^{2}$ Universitat Oberta de Catalunya, Barcelona, Spain

\begin{abstract}
Language teaching is a field in constant evolution, and the use of technology has boosted its development. However, there is a need to investigate the effects of technology on the development of pedagogical practices and their effects on learning outcomes. This study explores the deployment of correction strategies and repair moves in synchronous learning activities in an online English course. The study uses a mixed-methods approach that combines qualitative and quantitative research methods. The main findings of this investigation show that synchronous learning activities prompt the production of explicit corrections. The results also show that the deployment of explicit corrections generate the production of repair moves that lead to learning.
\end{abstract}

Keywords: Computer-mediated communication, Correction strategies, Repair moves, Synchronous learning activities

\section{Introduction}

The use of computer-mediated communication (CMC) technologies that target L2 learners has recently proliferated. These technologies provide language teachers with new tools. However, their implementation generate concerns for both teachers and researchers (Gleason \& Suvorov, 2011). In addition, the use of CMC tools provides learning opportunities to develop reading, listening, and grammatical skills. Moreover, the advent of technological development in synchronous tools, which use audio and video, provide learners with opportunities to develop speaking skills as well. However, issues such as, the effects on teachers' pedagogical practices, when synchronous technologies are used (Oztok, Zingaro, Brett, \& Hewitt, 2013), the effects of synchronous CMC tools on learning outcomes (Hirotani, 2009), and the effects of synchronous tools on the language output of the students (AbuSeileek \& Qatawneh, 2013) start to appear as concerns for teachers and researchers.

Oztok et al. (2013) believe that CMC tools have a strong social presence and numerous communication strategies and Hirotani (2009) claims that CMC tools provide a wide range of discourse patterns. According to AbuSeileek and Qatawneh (2013), the implementation of CMC tools in language teaching is based on the assumption that using the technology-enhanced language learning approach can promote interaction and communication between EFL learners, which may support their efforts to produce more linguistic output. Abrams (2003) suggests that CMC helps learners actively

(c) The Author(s). 2018 Open Access This article is distributed under the terms of the Creative Commons Attribution 4.0 International License (http://creativecommons.org/licenses/by/4.0/), which permits unrestricted use, distribution, and reproduction in any medium, provided you give appropriate credit to the original author(s) and the source, provide a link to the Creative Commons license, and indicate if changes were made. 
interact and negotiate with their peers and develop their communicative competence. Although a great body of research has investigated the benefits of CMC for language learning, there is still a need to investigate their effects on the strategies that teachers deploy to correct students' errors as well as to investigate the repair moves that the deployment of correction strategies generates. This study focuses on the effects of synchronous learning activities on the deployment of correction strategies and the selection of repair moves among a group of students learning English online. This investigation is a case study with a mixed-methods approach that combines both quantitative and qualitative research methods and uses a quasi-experimental, or nonequivalent, group design as the research procedure because it observes a single group (Creswell, 2013). The research data are drawn from the oral performances in synchronous learning activities and the participation in a focus group and in-depth interviews. The study uses the clause as basic unit of analysis, and it uses the error-treatment sequence to identify the reaction from the teacher to errors and the subsequent reaction from the student to the correction from the teacher. This study analyzes the oral performances of seven students and one teacher. This study seeks to answer these research questions: (1) What kind of error correction strategies do teachers deploy when interacting with students in synchronous learning activities? (2) Do these correction strategies translate into repair moves? (3) How do the students sense the teacher's corrections when errors take place? And (4) how do the students think they react when errors take place? Findings show that the synchronous learning activities provide opportunities to stretch the participants' language repertoire. This study also shows that the deployment of explicit corrections leads to the selection of successful repair moves. The results from this study also identify a need to train teachers to use the production of errors as instances to have more talking time.

\section{Literature review}

\section{Computer-mediated communication (CMC)}

The term computer-mediated communication refers to communication that takes place between people via the instrumentality of computers (Hampel, 2014; Herring, 2004). To date, several studies have identified the advantages of CMC tools for both students and teachers. For example, Peters and Hewitt (2010) acknowledge that students feel attracted to $\mathrm{CMC}$ tools because they offer the flexibility of learning at the time and place of their choice and teachers value their collaborative potential. Although most of the research has focused on written $\mathrm{CMC}$ and research in the field of $\mathrm{CMC}$ using video and audio is still scarce, previous studies have shown that the use of video conferencing as a CMC tool in language learning can foster collaborative learning through social interaction with both tutors and peers (Hampel \& Hauck, 2004; Rosell-Aguilar, 2005). Hampel (2014) states that CMC facilitates communication and understanding and improves communication and interaction with software that is enriched with text, images, whiteboards and text chat facilities.

CMC may be classified into synchronous and asynchronous communication. For the purpose of this study, I will only explore the term synchronous communication. Synchronous communication involves real-time communication between teachers and students (Oztok et al., 2013). It requires immediate responses, which limits the use of 
outside resources (AbuSeileek \& Qatawneh, 2013). Synchronous communication tools can pursue different purposes in language teaching. For example, enhancing linguistic interaction and fostering contact between different groups of learners. They can produce a large amount of output because they enable extensive learner-to-learner negotiation, more talking time per learner and more lexicon use than face-to-face communication. Gleason and Suvorov (2011) and Lee (2011) identify several advantages of CMC in promoting communication, interaction and socialization, which Table 1 summarizes.

\section{Corrective feedback}

Correction strategies are teacher and peer responses to learner's erroneous second language production (Yang, Chuang, Li, \& Tseng, 2013). They are also reactions used by teachers in response to learners' errors (Jepson, 2005; Lyster \& Ranta, 1997; Nassaji, 2007). A seminal study in this area is the work of Lyster and Ranta (1997) that categorizes correction strategies as explicit corrections, recasts, elicitations, metalinguistic clues and clarification requests. They point out that explicit corrections refer to the explicit provision of the correct form indicating that the student's utterance is incorrect. Recasts involve the teacher's reformulation of the complete or part of a student's utterance. Sagarra and Abbuhl (2013) state that recasts are reformulations of all or part of a learner's immediately preceding utterance in which one or more non target-like items is/are replaced by the corresponding target language forms and where, throughout the exchange, the focus of the interlocutors is on meaning, not language as object. Recasts are an ideal correction strategy because they provide immediate feedback about incorrect utterances in an unobtrusive way. They also provide a model of target-like input. However, learners need training that help them notice the corrective nature of recasts. Lyster and Ranta (1997) adopt this term from the L1 acquisition literature and cite other terms such as paraphrase (Spada \& Frohlich, 1995) and repetition with change and repetition with change and emphasis (Chaudron, 1977). Teachers employ clarification requests to indicate to students that an utterance has been misunderstood or that the utterance is inaccurate and that it needs a repetition or a reformulation. Sarandi (2016) defines clarification requests as a scaffolding to create understanding. Metalinguistic clues are comments, information or questions related with the formation of a student's utterance and do not explicitly provide the correct form. This strategy provides grammatical metalanguage that refers to the nature of the error (Lyster \& Ranta, 1997). Monteiro (2014)

Table 1 Advantages of CMC in promoting communication, interaction and socialization (Gleason \& Suvorov, 2011; Lee, 2011)

\begin{tabular}{ll}
\hline CMC has been found to & Provide frequent opportunities to express ideas and opinions \\
& Produce a large amount of target language output \\
& Allow more time to develop comments \\
& Lead to greater precision of expression or greater accuracy rates \\
& Promote a collaborative spirit \\
& Enhance motivation of language practice \\
& Promote a student-centered atmosphere \\
& Reduce students' anxiety \\
& Develop students' linguistic performance \\
\hline
\end{tabular}


states that metalinguistic feedback is information about the error committed without the correct form. Lyster and Ranta (1997) claim that metalinguistic clues provide negative evidence and are explicit. Elicitations are a direct reformulation of a student's utterance by asking questions, by pausing to allow students to complete the teacher's utterance or by asking students to reformulate an utterance. Sarandi (2016) classifies elicitations as explicit and output pushing. They are explicit because the corrective force of feedback is salient to learners and they are output pushing because learners are required to work out the correct form of their utterance using their own language repertoire. Repetitions refer to the teacher repeating the students' ill-formed utterance, adjusting intonation to highlight the error (Jepson, 2005; Lyster \& Ranta, 1997; Nassaji, 2007). Table 2 summarizes the categorization of correction strategies and their definitions.

\section{Repair moves}

Repair moves are students' reaction to teachers' correction that are generated implicitly or explicitly to the various negotiation types of corrective feedback e.g., recasts, elicitations, clarification requests (Nassaji, 2007). Repair moves are also practices for dealing with problems or trouble in speaking, hearing and understanding in conversations or as learner uptake (Lyster \& Ranta, 1997).

(Lyster \& Ranta, 1997) divide repair moves in successful and non-successful repair moves. Successful repair moves lead to corrections, they are repetitions of teacher's correction, incorporation of teacher's correction, self-repairs and peer repairs. Non-successful repair moves do not lead to correction; they result in providing a yes/no answer or hesitating and making the same or a different error. Non-successful repair moves are also responses to the teacher's feedback, but without including any reference to the error or reacting to the teacher's feedback, but the reaction only includes part of the initial error. Tables 3 shows the different types of repair moves and their definition.

\section{Method}

\section{The course and the synchronous learning activities}

The research scenario of this study is an online English course named Development of Oral Skills (DOS), which aims to enable students to express their opinions and thoughts while meeting a variety of qualitative objectives of spoken language use

Table 2 Corrections, their definition based on Lyster (2001), Lyster and Ranta (1997)

\begin{tabular}{|c|c|}
\hline Correction strategy & Definition \\
\hline Recasts & $\begin{array}{l}\text { A recast is what the teacher says with the purpose of helping a student notice his or } \\
\text { her mistakes. Teacher implicitly reformulates all or part of the student's utterance. }\end{array}$ \\
\hline Elicitation & $\begin{array}{l}\text { Elicitation is a technique by which the teacher gets the learners to give information rather } \\
\text { than giving it to them. Teacher directly elicits a reformulation from students by asking } \\
\text { questions. }\end{array}$ \\
\hline Explicit corrections & $\begin{array}{l}\text { Teacher supplies the correct form and clearly indicates that what the student had said } \\
\text { is incorrect. }\end{array}$ \\
\hline $\begin{array}{l}\text { Repetitions from } \\
\text { the teacher }\end{array}$ & $\begin{array}{l}\text { Repetition of all or part of the utterance containing the error, often accompanied by a } \\
\text { change in intonation }\end{array}$ \\
\hline Clarification requests & An utterance indicating a problem in comprehension, accuracy or both \\
\hline $\begin{array}{l}\text { Metalinguistic } \\
\text { feedback }\end{array}$ & $\begin{array}{l}\text { Comments, information or questions that may or may not contain metalanguage but } \\
\text { do not include the reformulation related to the ill-formedness of the utterance }\end{array}$ \\
\hline
\end{tabular}


Table 3 Successful and non-successful repair moves and what they refer to according to Lyster and Ranta (1997)

\begin{tabular}{|c|c|c|c|}
\hline $\begin{array}{l}\text { Successful } \\
\text { repair moves }\end{array}$ & Definition & $\begin{array}{l}\text { Non-successful } \\
\text { repair move }\end{array}$ & Definition \\
\hline Repetitions & $\begin{array}{l}\text { A student's repetition to the } \\
\text { teacher's feedback }\end{array}$ & Yes/no answer & $\begin{array}{l}\text { A simple yes or no answer } \\
\text { to the teacher's feedback }\end{array}$ \\
\hline Incorporations & $\begin{array}{l}\text { A student's repetition of the } \\
\text { correct form provided by the teacher }\end{array}$ & Hesitations & $\begin{array}{l}\text { A student's hesitation to } \\
\text { the teacher's feedback }\end{array}$ \\
\hline Self-repairs & Self-corrections & Same error & A repetition of the same error \\
\hline Peer repairs & $\begin{array}{l}\text { Peer corrections provided by } \\
\text { another student or classmate }\end{array}$ & Different error & $\begin{array}{l}\text { A response to the teacher's } \\
\text { feedback, but including a } \\
\text { different error }\end{array}$ \\
\hline
\end{tabular}

(range, accuracy, fluency, interaction and coherence) based on the Common European Framework of Reference for Languages (CEFR) (Council of Europe, 2001). I designed the course for students who have a basic command of English (A2, B1 according to the CEFR). DOS runs on three propositions. First, it is a content-based course because the language is acquired through the study of a series of topics, each topic is exploited in systematic ways and from different angles, so the role of grammar structures is incidental (Jalilzadeh \& Tahmasebi, 2014). Second, it is a task-based course because its activities have particular goals, and their focus is communication (Ellis, 2003; Hismanoglu \& Hismanoglu, 2011; Klapper, 2003). Third, DOS uses synchronous (online lessons and online interviews) and asynchronous (audio forums, video forums and podcasts) learning activities. For the purpose of this investigation, I will only focus on the synchronous learning activities in the DOS course.

\section{Synchronous learning activities}

The synchronous learning activities are the online lessons and the online interviews. The online lessons are synchronous sessions that employ a video conference tool. They have: (1) a pre-task stage, which aims to activate background knowledge and helping participants become familiar with possible unknown words or expressions, (2) a during-task stage, in which participants have to work with information in the target language, and (3) a post-task stage, in which participants have to create a final learning product with the information and language learned in the previous stages (Ellis, 2003; Willis, 1996). The online interviews take place between the teacher and one student at a time because they are assessment activities. In one part of the online interviews, the participants introduce themselves; in another part, the teacher asks questions about the topics discussed in the previous online lessons. Each online interview has a set of guidelines that aims at solving technical issues and assessment issues, and they provide a glimpse of the tasks during the interview. During the synchronous learning activities, participants can use video or only audio to communicate, and students can interact with the teacher or with other students using a chat room as backchannel. Figure 1 shows the interface of an online lesson.

\section{Data sources}

There were two sources of data for this study: (1) the oral performances in the synchronous learning activities (the online lessons and the online interviews) and (2) the 


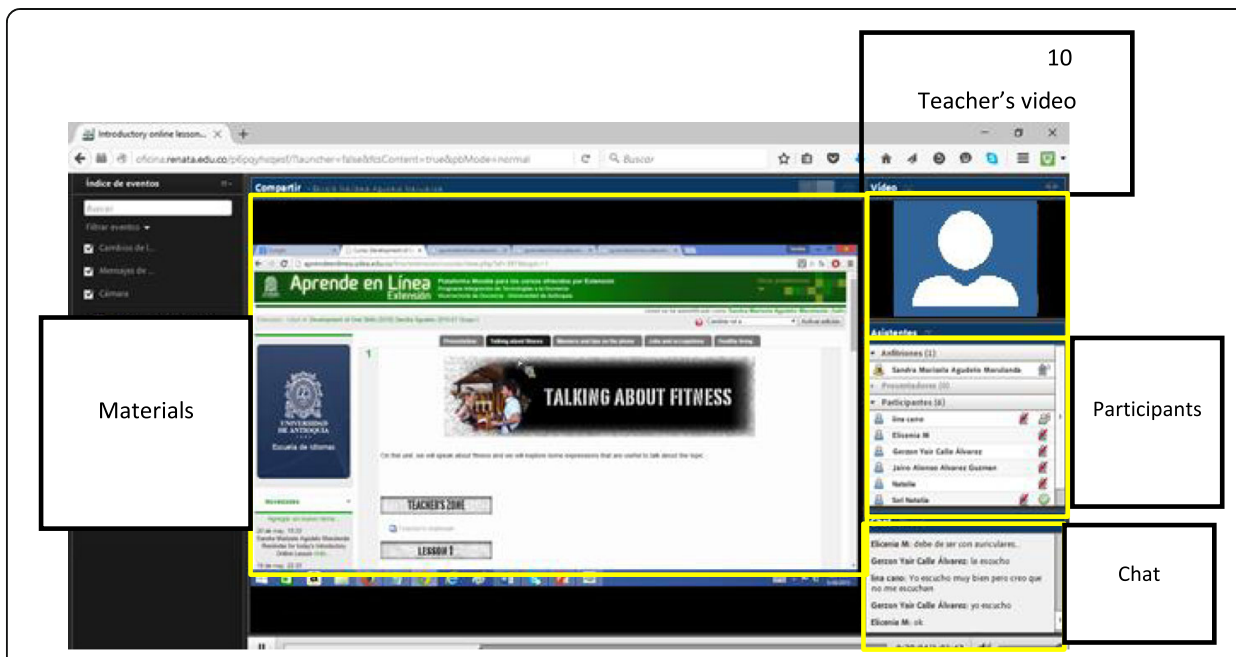

Fig. 1 Interface of an online lesson

participation in a focus group with students in which six students participated and two in-depth interviews: one with the one student and another one with the teacher An audio editor and recorder was used to capture the oral performances in the synchronous learning activities and to transform those performances into mp3 files to facilitate their storage, manipulation and transcription. The oral interactions were transcribed verbatim and compared with the audio to ensure inclusiveness and clarity. The interviews and the focus group were semi-structured, and they utilized protocols for their administration. The study followed these steps to gather the information from the indepth interviews and the focus groups. First, sending the participants an email that explained the study; it guaranteed anonymity and asked for an appropriate time and place to carry out an in-depth interview or focus group session. Second, the protocols for the interviews or the focus groups were prepared based on the research questions and some preliminary observations of oral performances in the course. And third, the recordings were transcribed verbatim for analysis. Figure 2 shows the process of capturing the oral performances from the course and the information from the in-depth interviews and the focus groups.

\section{Analysis}

The study used content analysis and discourse analysis to analyze the transcripts from the oral performances in the synchronous learning activities (online lessons and online interviews). The basic unit of analysis employed was the clause, understood as an utterance containing a finite verb as a predicate (Delahunty, Jones, \& Verenikina, 2014; Espasa, Guasch, \& Alvarez, 2013). After identifying the clauses, the correction strategies (Table 2) and the repair moves (Table 3) were identified based on Lyster and Ranta's (1997) categorization of correction strategies and repair moves..

To identify the correction strategies and the repair moves in the synchronous learning activities, this study adapted the error-treatment sequence proposed by Lyster and Ranta (1997). Once the clauses were identified, the following step was identifying the clauses that contained at least one error. The next step was to search for the reaction 


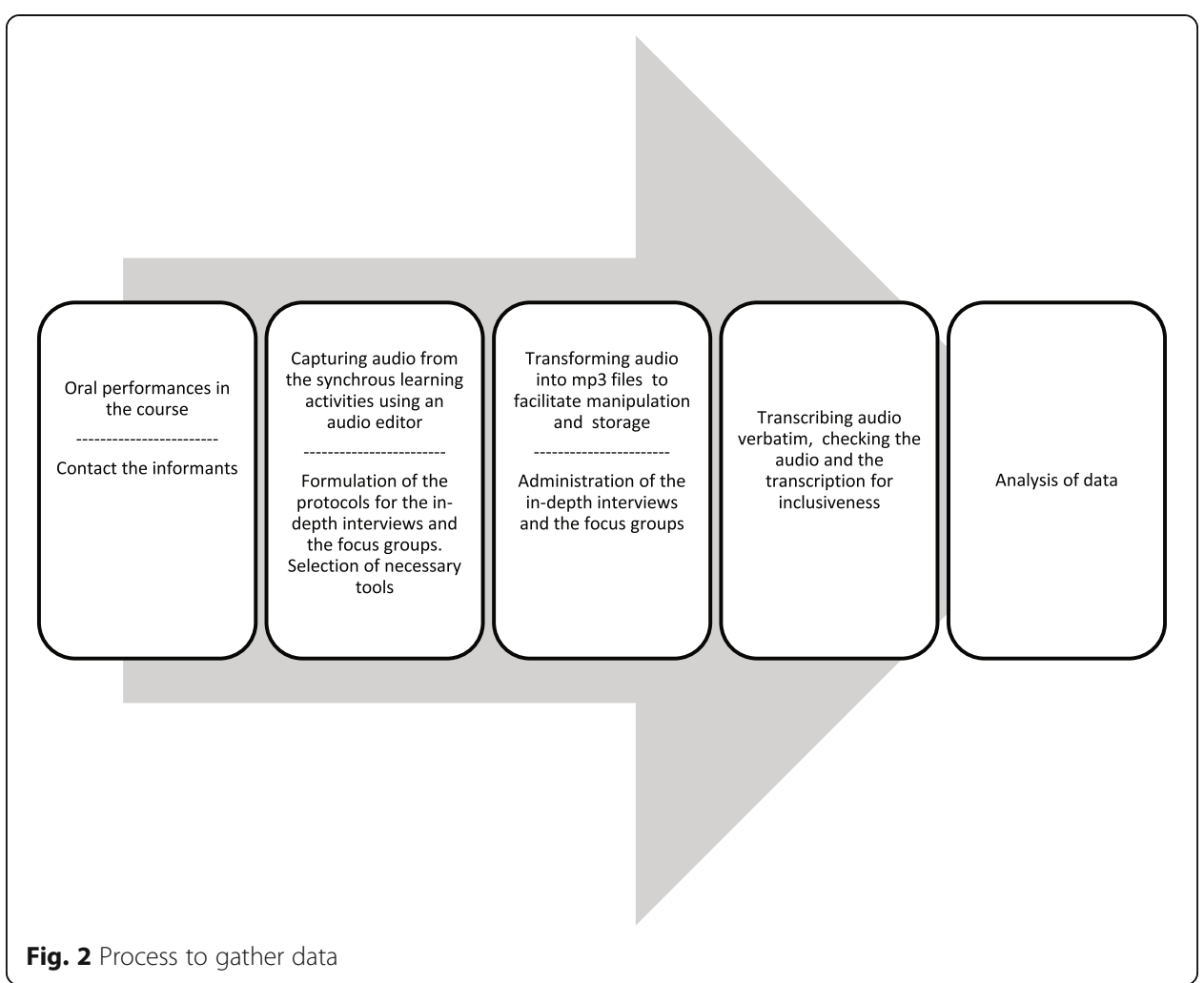

from the teacher (correction strategy) and the subsequent reaction from the student to the correction by the teacher (repair move). This procedure allowed the researcher to tag the clause, the error, the learning activity where the error took place, the participant who made the error, the correction strategy the teacher employed, and the reaction from the student. Table 4 shows the categorization of corrections strategies and repair moves employed in this study.

Table 4 Codes for correction strategies and repair moves based Lyster and Ranta (1997)

\begin{tabular}{ll}
\hline Correction strategies & Codes \\
Explicit corrections & E_C \\
Recasts & $R$ \\
Elicitation & E \\
Metalinguistic clues & M_L_C \\
Clarification requests & C_R \\
Repetitions from the teacher & R \\
Repair move & Code \\
Student repeats the teacher's correction & STU_REPEAT \\
Student incorporate the teacher's correction & INCOR_TS_REF \\
Student self-repairs & SELF_REP \\
Student provides a yes/no response & YES_NO_REP \\
Student hesitates & HESIT_REP \\
Student makes the same mistake & SAME_MISTA_RE \\
Student partially repairs & PART_REAP \\
\hline
\end{tabular}


The data extracted from the students' oral production in the synchronous learning activities were analyzed in two phases. The first phase was the identification of the presence or absence of correction strategies such as explicit corrections, clarification requests, or repair moves such as repetitions, incorporations, and so. For this identification, ' 1 ' indicated the presence and ' 0 ' indicated the absence of the previously mentioned items. In this phase, the frequency of occurrence of correction strategies, and repair moves was identified. This investigation employed a matrix with 33 columns in an MS Excel spreadsheet to register those data. The second phase classified the results from the previous analysis into big categories: correction strategies, repair moves, synchronous technologies, less explicit and more explicit correction strategies, unsuccessful repair moves, and successful repair moves. This phase provided a wider view of the data and I was able to establish relationships among the data. For example, synchronous technologies and type of correction strategies or more explicit correction strategies and successful repair moves. The data on this level allowed to use descriptive statistics to present the results from both analyses in the form of graphs and tables using SPSS.

The transcripts from the in-depth interviews to the students and to the teacher and the focus group to students were analyzed using open codes, which refer to major categories of information and then with axial codes, which refer to the categories that emerge from the major categories. Open codes and axial codes help categorize and synthesize the emerging themes (Creswell, 2007). Figure 3 summarizes the process to analyze the data gathered from in-depth interviews and the focus group.

\section{Results}

\section{Synchronous learning activities and the deployment of correction strategies}

During the synchronous learning activities, the teacher provides corrective feedback and employs different correction strategies to fix the students' inaccuracies that emerge in the course of interaction. The analysis shows that there are 246 clauses that contain a correction strategy in the synchronous learning activities (online lessons and online interviews) that represent $7 \%$ of the total number of clauses in the course (3725).

Figure 4 shows that the teacher prefers to use explicit corrections as they are in $75 \%$ (185 clauses) of the 246 clauses in the synchronous learning activities, followed by recasts as they are in $22 \%$ of the clauses in the synchronous learning activities (54 clause). Figure 4 also shows that the deployment of elicitations and metalinguistic clues is not very frequent in the synchronous learning activities. This suggests that in an attempt to make errors salient, the teacher provides the explicit correction to errors to make sure that the students notice them and correct them. Similarly, the teacher prefers explicit correction strategies that unfortunately do not foster the use of the foreign language rather than implicit correction strategies.

\section{Relationship between correction strategies and repair moves}

The production of repair moves triggered by the deployment of corrective feedback suggests a low degree of learners' immediate response following the teacher's error correction.

This analysis shows that when the teacher deploys correction strategies there are only 100 clauses where there are reactions from the students, which represent almost $3 \%$ of 


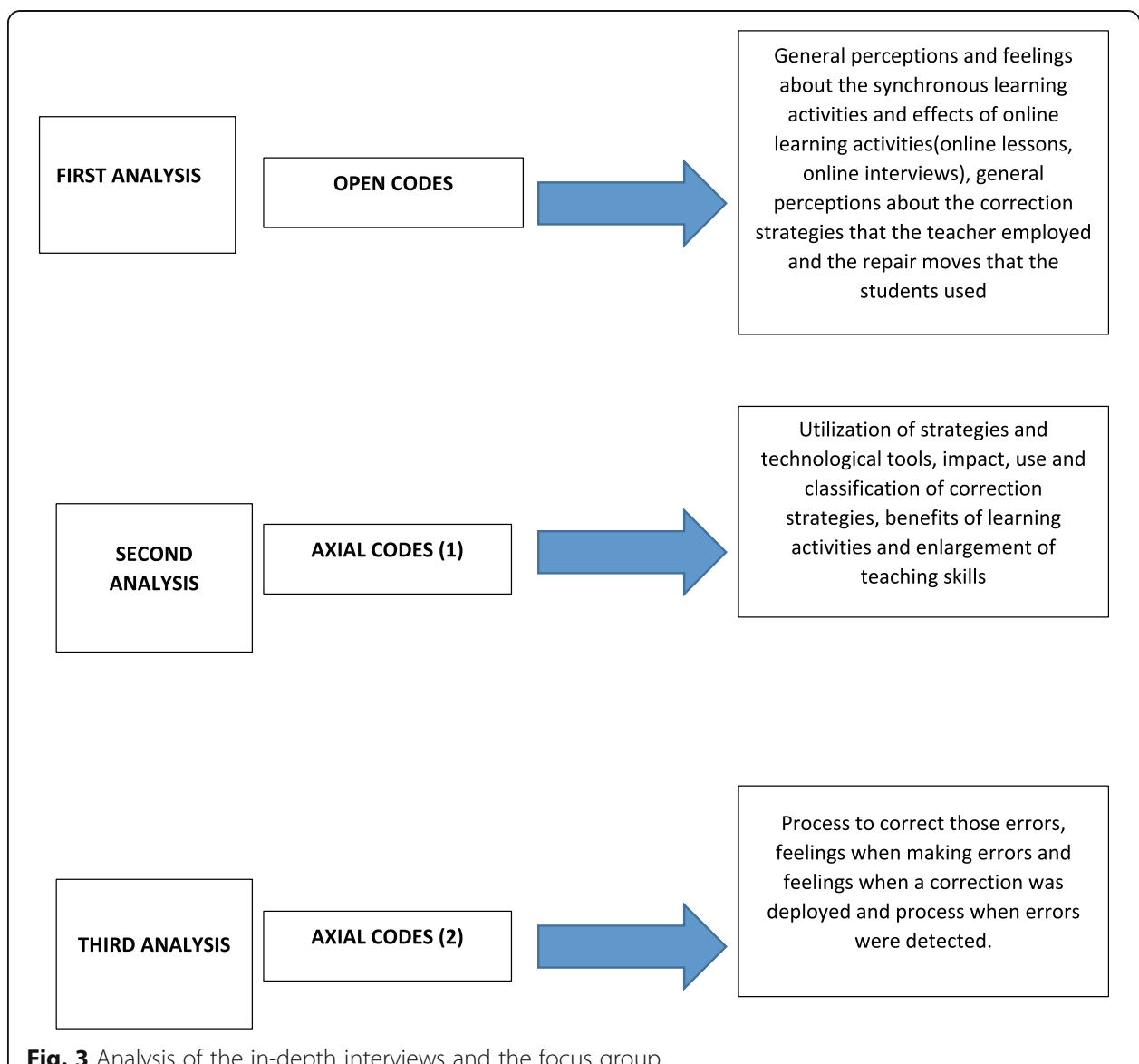

Fig. 3 Analysis of the in-depth interviews and the focus group

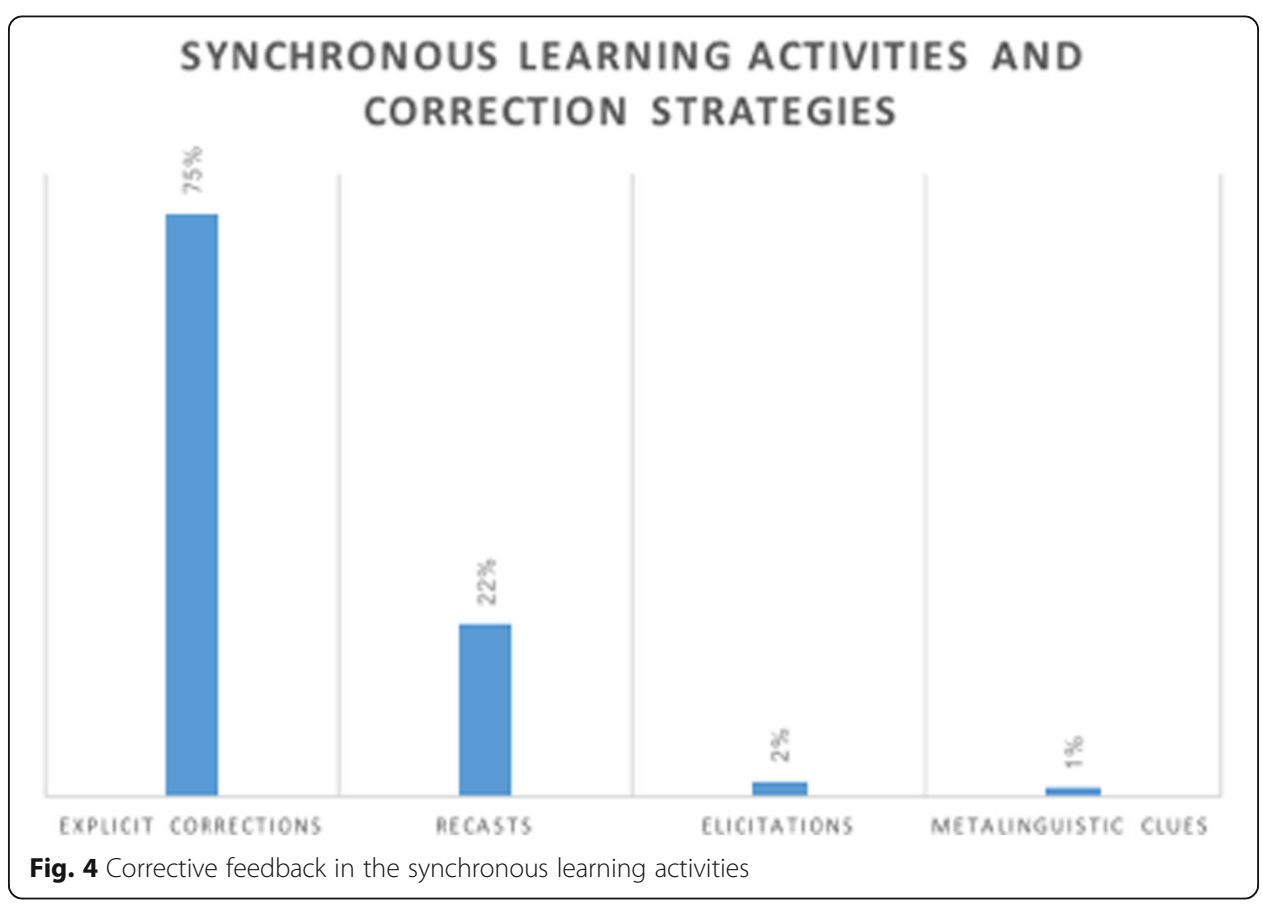


the total number of clauses in the course (3725). A closer look at those clauses shows that 50 and $21 \%$ (50 and 21 clauses) of them contain the repetition of the teacher's correction and they happen when the teacher deploys explicit corrections and recasts. Eight and five percent of the clauses ( 8 and 5 clauses) that have repairs contain the incorporation of the teachers' correction in a subsequent clause and they appear when the teacher explicitly provides feedback to a student's inaccuracy or when the teacher reformulates an error. Self-repairs are very scarce and they derive from explicit corrections in only $4 \%$ of the clauses ( 4 clauses) and in $3 \%$ of the clauses (3 clauses) when the teacher deploys recasts. Three percent of the clauses that have repairs contain the repetition of the teacher's correction (3 clauses) and they appear when the teacher deploys elicitations and just $2 \%$ of the clauses that have repair moves originate when the teacher deploys explicit corrections. Finally, when the teacher spots an error and deploys a metalinguistic clue, a yes/no response appears in only $1 \%$ of the clauses (1 clause) that have repair moves. The results shows that despite being not very numerous, the deployment of correction strategies derives in more successful repair moves (repetition from the teacher's correction, incorporation of the teacher's correction and self-repairs) that lead to amending inaccuracies and therefore lead to learner uptake of either noticing or actual acquisition of problematic language items on more occasions than unsuccessful repair moves that end in yes/no responses and hesitations and thus do not lead to fixing the students' ill-formed clauses. Figure 5 shows the production of repair moves triggered by the deployment of correction strategies.

These observations show that the teacher explicitly corrects the errors that the students produce or reformulates the inaccurate clause in an attempt to make errors salient and noticeable. The students, on the other hand, mostly react to the correction

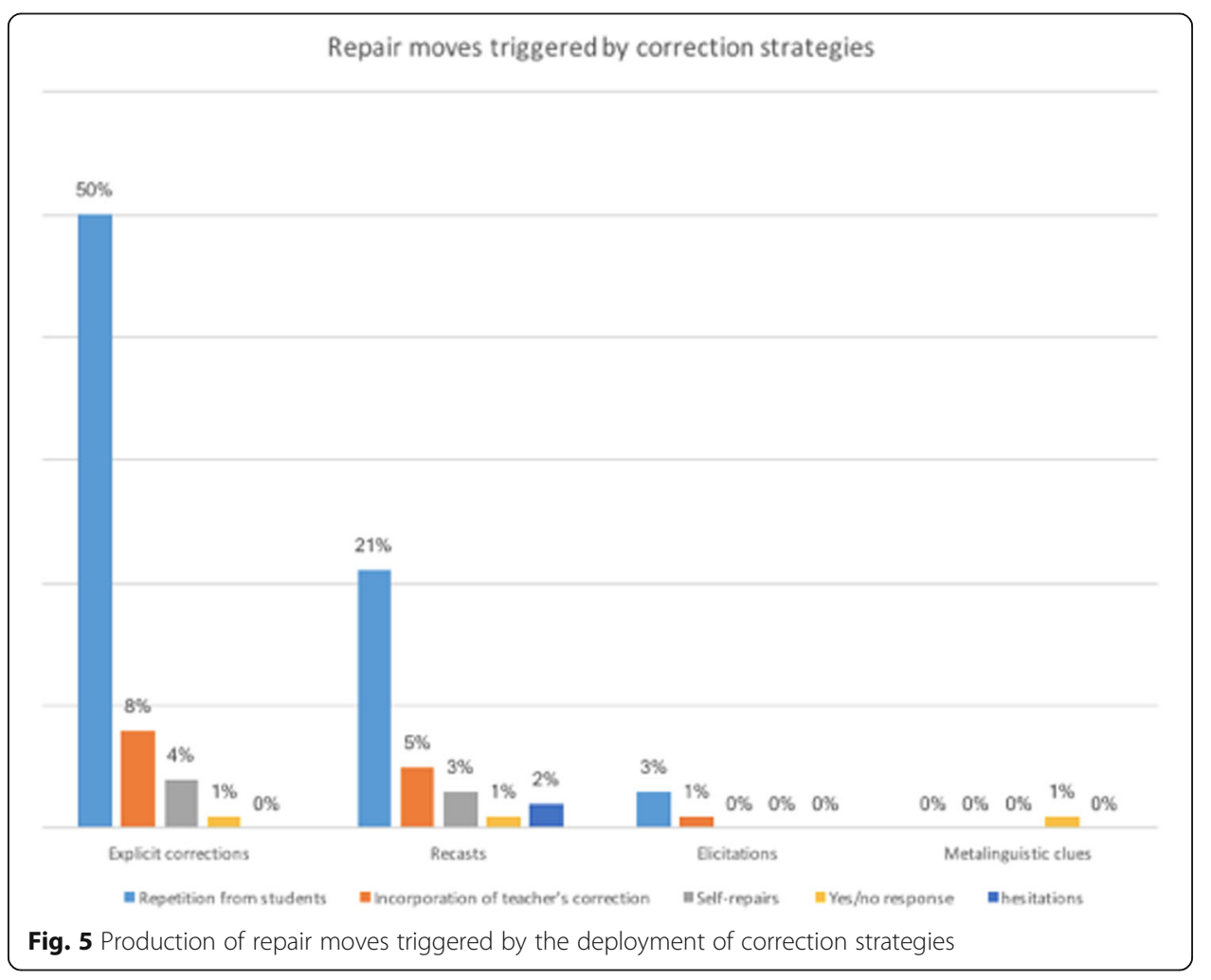


from the teacher by repeating the correction and in fewer cases by incorporating the correction in a subsequent clause.

\section{Perceptions of the deployment of correction strategies and repair moves}

The following are the perceptions the teacher and the students have of the deployment of correction strategies, the use of repair moves and self-repairs in the synchronous learning activities. When asked about how the teacher corrected errors and what type of errors were corrected in the online lessons and the online interviews, some participants refer to a two-sided deployment of correction strategies as errors that emerge in different learning activities in the DOS course generate explicit corrections, which the teacher highlights in the online lessons.

When there were errors that I identified in the recordings, I provided a general feedback, I outlined them and provided the exact correction in the next online lesson. (interview with the teacher)

When asked about the type of errors that were corrected and the type of correction strategy employed, participants allude to the use of explicit corrections in the online lessons to fix grammar and pronunciation problems as the teacher explains that she provides the explicit correction when she spots an error. She also highlights that she has students repeat her corrections in order to help them be aware of the error and the way to correct it and to engage them in an error-correction process.

In the online lessons, if they [the students] made a pronunciation or a grammar error, I explicitly corrected them and I had them repeat the correction. If they [the students] made the error again, I stopped and repeat the correction again and I had them repeat again until they got it right. (In-depth interview with the teacher)

When asked to elicit the most frequently corrected errors in the online lessons and the most common strategies employed to correct them, some participants identify vocabulary, grammar and pronunciation errors as the most common errors and the provision of the correct answer as the most common strategy employed by the teacher.

The teacher always gives us the correct answer and she gets us repeat when we make a mistake and errors with vocabulary, pronunciation and grammar are the most common in the online lessons and the online interviews, I think. (In-depth interview to students)

When asked to identify the benefits of the synchronous learning activities concerning the correction of errors, the participants point out that events and actions are unpredictable in the online lessons and the online interviews, which provide students with an opportunity to stretch their command of the language. They have to repair inaccuracies with vocabulary, pronunciation and grammar as soon as they happen. The participants identify the immediacy of the teacher to correct an error as soon as she detects one as an asset that helps them repair their errors. This is evident in these excerpt from the in-depth interview to the students. 
What happens in the online lesson is unforeseeable and when I have to talk about unknown topics that causes me trouble and I make a lot of mistakes, but at the same time I have the chance to correct those mistakes as soon as they happen and broaden my knowledge of the language. (In-depth interview to students)

The repetition of the teacher's correction is the most frequent repair move that appears in the DOS course as the analysis of the oral performances shows, students allude that this repair move helps them understand linguistic features. A student explains that she repeats what the teacher says and it helps her improve the development of speaking skills when asked to think about her reactions to the teacher's corrections in the online lessons and the online interviews.

[...] the conversations (online lessons and online interviews) were a very demanding activity and in these conversations, there was immediate correction of errors and when the teacher corrected me, I immediately repeated what the teacher said trying to understand. It helped me a lot. (In-depth interview with students)

The repetition of the teacher's correction is not a spontaneous reaction; rather the teacher promotes it as part of her teaching repertoire. She elicits the use of repetitions to correct pronunciation inaccuracies in the online lessons and the online interviews. This is evident in this segment from the in-depth interview to the teacher where she explains that she pays attention to the errors the students produce; she corrects their errors and has them repeat the correction because it is part of their learning process.

When they [the students] mispronounced a word, I didn't interrupt them to correct them, what I did, instead, was to repeat the word or the sentence correctly. I did that not because I wanted to embarrass them, I did it as part of my speech, naturally, so they could notice where the error was. (In-depth interview with the teacher)

\section{Discussions}

\section{Synchronous learning activities and the deployment of correction strategies}

The results from the present study show that the preferred correction strategies are explicit corrections and recast. The results from the present study are in good agreement with a study carried out by Fiori (2005) that sought to examine grammatical development in synchronous computer-mediated communication, she found a higher amount of explicit corrections, and those explicit corrections revolved mostly around vocabulary inaccuracies. A possible explanation for the extensive deployment of explicit corrections found in the present study is that the teacher felt the need to call direct attention to the nontarget-like utterances. According to Fiori (2005), providing the explicit correction to an error generates opportunities to pay attention to the error, to comprehend its nature and there are more chances to correct it. Another explanation why the deployment of explicit corrections outperformed the deployment of other correction strategies in this study is rooted in the low linguistic level of the participants in the DOS course who need more explanations and whose limited resources do not allow them to process less explicit types of feedback (Sarandi, 2016). The production of 
correction strategies is low, as the results from this investigation show, which indicates that the teacher only reacts to a limited number of errors. These results are in good agreement with a study carried out by (Monteiro, 2014) that shows that the participants in activities embedded in a videoconference tool produced a higher number of instances containing incorrect target forms when compared with the instances providing feedback. Monteiro (2014) concludes that although the production of incorrect target forms is higher than the production of feedback, or correction strategies, corrective feedback is effective at helping learners develop knowledge of the target language.

The results from the present study suggest that the deployment of correction strategies in the synchronous learning activities is twofold. On the one hand, the teacher uses the synchronous learning activities to promote interaction that turns into learning, and on the second hand, she employs the synchronous learning activities as a vehicle to provide feedback from inaccuracies that originate in the asynchronous learning activities by extensively deploying explicit corrections. In other words, by explicitly providing the target-like reformulation of an error (Lyster \& Ranta, 1997). A possible explanation for this is rooted in the assertion that feedback messages are invariably complex and difficult to decipher and the teacher, in this case, tries to assure that her students realize exactly their inaccuracies by providing them opportunities to construct actively an understanding of the feedback messages she deploys (Van Maele, Baten, Beaven, \& Rajagopal, 2013).

The findings from the present study reveal that the students sense the use of correction strategies to help improve understanding of grammar aspects, to build vocabulary and to master pronunciation features. A number of studies have proven the effectiveness of correction strategies to develop different aspects of the target language. For example, Monteiro (2014) concluded that the mobilization of correction strategies helps develop implicit and explicit knowledge of the target language, they also help master articles (Sauro, 2009, pag. 113), noun-adjective agreement (Sagarra \& Abbuhl, 2013, p. 212) and help improve pronunciation and master several grammar features (Sheen, 2006, p 386).

\section{Synchronous learning activities and repair moves}

The results from this study indicate that the most common repair moves are successful repair moves, which are the ones that lead to correction and are the ones that are more suitable for learning to take place (Nassaji, 2007). These findings show that repetitions of teacher's corrections report the highest rates followed by the incorporations of teacher's correction. This suggests that when performing in the synchronous learning activities, a student makes an error, which the teacher spots and tries to make it salient to the student. Once the student notices the error, he tends to repeat the correction in an attempt to internalize the new structure and as consequence; his performance improves on particular target language feature because his language awareness is raised (Heift, 2010).

However, the results from this investigation show that the number of clauses containing repairs is lower than the number of clauses containing feedback from the teacher and the number of clauses containing feedback from the teacher is lower than the number of clauses that contain errors. This indicates that in the course of interaction in the synchronous learning activities, teachers have a number of tasks to perform. They must support students by providing a structure of the learning content, they have 
to stimulate students' motivation and provide feedback of accomplishment (Paechter \& Maier, 2010). Students, on the other hand, have to provide immediate responses with limited resources (AbuSeileek \& Qatawneh, 2013).

\section{Repair moves triggered by correction strategies}

After having analyzed the clauses that contain correction strategies and repair moves in the synchronous learning activities, the findings from the present study indicate that the use of explicit corrections and recasts trigger the repetition and the incorporation of the teacher's corrections. These findings agree with Sauro's (2009) results as she found that the output of the deployment of explicit corrections is the repetition or identification of errors and the output produced by recasts is the reformulation or the incorporation of errors in subsequent utterances. These results also agree with Sarandi (2016) as he claims that recasts have proven to be more effective in terms of language learning because they encourage learners to self-correct and they have shown better results in terms of learning of language structures. Similarly, Sagarra and Abbuhl (2013) suggest that recasts are effective in learning new language structures because they lead to more targetlike modified output.

The findings from this study reveal that the use of metalinguistic clues generates the repetition of the correction from the teacher. The findings from the present study concur with other studies that have found that metalinguistic feedback provides comments, information or questions related to the ill-formedness of the utterance. Metalinguistic clues are expected to produce the identification of errors and sometimes reformulations (Sauro, 2009). Monteiro (2014) provides an explanation for this in a study that aimed to explore the deployment of corrective feedback in video-conferencing as she claims that metalinguistic feedback forces learners to access and retrieve target forms from memory (p68). Her study concludes that metalinguistic feedback activates different cognitive processes and it is effective for the development of implicit and explicit knowledge of the target language and it helps develop knowledge of target structures. The present study found that when the teacher deploys elicitations, they generate the repetition and the incorporation of the correction from the teacher at a very low level. Nassaji (2007) explains the low effect of elicitations as he states that elicitations are slightly associated with the production of repair moves that lead to corrections or successful repairs such as incorporations of the teacher's corrections. Lyster and Ranta (1997) and Sauro (2009) also explain the low effect of elicitation as they claim that elicitations can only lead to the identification of the error.

The production of repair moves that are generated by the deployment of correction strategies in the present study suggests that the use of correction strategies is convenient in the learning process in online environments. Although the participants in the study do not identify the repair moves they use when the teacher corrects them, they highlight that the use of correction strategies helps repair pronunciation problems, it fosters the development of speaking skills and it facilitates the identification of errors. These findings seem to support studies that show the effectiveness of corrective feedback in the production of successful repair moves. For example, Kartchava and Ammar (2014) looked into the effectiveness of corrective feedback in relation to the noticeability of English past tense and they found that the students who were treated with 
corrective feedback were able to notice the target grammatical structure significantly more and their levels of learning of the target grammatical structure were also higher. Rolin-Ianziti (2010) in a study that explored the effects of corrections in the learning of grammar features found that there is a systematic organization of delayed correction. Finally, Yilmaz (2011) explored the relationship of synchronous computer-mediated communication and corrective feedback and the production of lexical, grammatical and orthographic errors. The study found that synchronous computer-mediated communication produced higher frequencies of language related episodes that contained correct forms of lexical, grammatical and orthographic instances.

\section{Conclusions}

\section{Deployment of correction strategies during synchronous learning activities}

A major finding from this study is that the deployment of explicit corrections is the preferred type of correction strategy. Although, explicit corrections do not foster the use of the target language as other correction strategies do, the corrective force of feedback is made salient to the learners helping notice their errors and increasing the level of language awareness and self-diagnosis. This investigation reveals that the extensive use of explicit corrections is the result of the need of the teacher to make errors salient and a response to the low linguistic level of students who seek clear answers that help them identify errors and make sense of the correction from the teacher.

This investigation has found that due to the communicative nature of the synchronous learning activities in this study, the deployment of recasts also take place at a lower level despite the numerous learning advantages that they have. Given the applied linguistics nature of the present study, a practical consequence of its findings reveals the existing need to show online teachers that regardless of the linguistic level of students, the use of unobtrusive, implicit and output pushing strategies such as recasts and elicitation bring beneficial effects to the development of language accuracy. Namely, they help learners notice their errors unobtrusively fostering connections and the use of the target language as a means rather than an end.

\section{Repair moves during synchronous learning activities}

The results from this investigation have shown that the most frequent reactions from students to the teacher's corrections are the repair moves that lead to corrections and subsequently facilitate learning, whereas self-initiated repair moves or self-repairs are seldom seen along this study. The scarceness of self-repairs in the synchronous learning activities in this study calls for the deployment of correction strategies that help students realize their errors and at the same time foster the use of the target language (recasts and elicitations).

The research has also shown that the repetition of the teacher's correction is the most common type of repair. Although the number of clauses containing successful repair moves is low, making an error salient can help the development of language accuracy, especially with students whose linguistic level is low. However, the use of unobtrusive, implicit and output pushing strategies have proven to be more effective to develop language accuracy as they foster the use of the target language and they help stretch the students' linguistic repertoire. These results suggest that the synchronous learning 
activities foster students to take control over their existing language level because by repeating or incorporating the correction from the teacher, the students attempt to automatize the development of their language accuracy by identifying their errors and trying to avoid committing them. This study has shown that although the participants think that repair moves are conducive to overcome linguistic problems, they can be more effective if teachers deploy unobtrusive, implicit and output pushing strategies that not only help students notice their errors, but also foster the use of the target language during the error correction process. A major conclusion of this investigation is that synchronous communication opens multiple possibilities for teaching languages online. They provide instances where interactions can take place naturally as they happen in face-to-face settings, they allow teachers to detect errors and they can make errors salient and learners can repair their inaccuracies as they take place. Besides, synchronous communication provide learners with opportunities to assure that in the online experience there are real people participating.

Funding

The author received no financial support for the research and/or authorship of this article.

\section{Availability of data and materials}

The data that support the findings of this study are available from the corresponding author upon reasonable request.

Author's contributions

JEP conceived the study, developed the paper and developed the manuscript of the paper. The author read and approved the final manuscript.

\section{Author's information}

Jorge Eduardo Pineda is an assistant professor at the Universidad de Antioquia in Medellín, Colombia. He is a doctoral student at the Universitat Oberta de Catalunya. His research interests are the relationship between language teaching and learning and technology, the effects of implementing technology in teachers' professional performance and the effects of technology in the teaching and learning of languages.

Competing interests

The author declares that he has no competing interests.

\section{Publisher's Note}

Springer Nature remains neutral with regard to jurisdictional claims in published maps and institutional affiliations.

Received: 27 November 2017 Accepted: 23 April 2018

Published online: 19 June 2018

\section{References}

Abrams, Z. I. (2003). The effect of synchronous and asynchronous CMC on oral performance in German. Modern Language Journal, 87(2), 157-167.

AbuSeileek, A. F., \& Qatawneh, K. (2013). Effects of synchronous and asynchronous computer-mediated communication (CMC) oral conversations on English language learners' discourse functions. Computers \& Education, 62, 181-190. https://doi.org/10.1016/j.compedu.2012.10.013.

Chaudron, C. (1977). A descriptive model of discourse in the corrective treatment of learners' errors. Language Learning, $27(1), 29-46$.

Council of Europe (2001). The common European framework of reference for Languages : Learning, teaching, assessment, (pp. 1-273). Council of Europe. https://doi.org/10.1017/S0267190514000221.

Creswell, J. W. (2007). Qualitative enquiry \& research design, choosing among five approaches, (2nd ed., ). https://doi.org/ 10.1016/j.aenj.2008.02.005

Creswell, J. W. (2013). Qualitative inquiry \& research design : Choosing among five approaches. Los Angeles: Sage.

Delahunty, J., Jones, P., \& Verenikina, I. (2014). Movers and shapers: Teaching in online environments. Linguistics and Education, 28, 54-78. https://doi.org/10.1016/j.linged.2014.08.004.

Ellis, R. (2003). Task-based language learning and teaching. Oxford: Oxford University Press.

Espasa, A., Guasch, T., \& Alvarez, I. M. (2013). Analysis of feedback processes in online group interaction: A methodological model. Digital Education Review, 23(1), 59-73.

Fiori, M. L. (2005). The development of grammatical competence through synchronous computer-mediated communication. CALICO Journal, 22(3), 567-602. https://doi.org/10.1558/cj.v22i3.567-602.

Gleason, J., \& Suvorov, R. (2011). Learner perceptions of asynchronous oral computer-mediated communication tasks using Wimba voice for developing their L2 oral proficiency. In S. Huffman, \& V. Hegelheimer (Eds.), The role of CALL 
in hybrid and .... Ames: lowa State University Retrieved from https://apling.engl.iastate.edu/alt-content/uploads/ 2015/05/tsll_gleason_and_suvorov_2011.pdf.

Hampel, R. (2014). Making meaning online: Computer-mediated communication for language learning. In Language as information. Proceedings from the CALS conference 2012, (pp. 88-106).

Hampel, R., \& Hauck, M. (2004). Towards an effective use of audio conferencing in distance language courses. Language Learning \& Technology, 8(1), 66-82 Retrieved from http://www.ltjournal.org/item/2460.

Heift, T. (2010). Prompting in CALL: A longitudinal study of learner uptake. Modern Language Journal, 94(2), 198-216. https://doi.org/10.1111/j.1540-4781.2010.01017.x.

Herring, S. (2004). Computer-mediated discourse analysis. Handbook of discourse analysis. Retrieved from http://odur. let.rug.nl/redeker/herring.pdf

Hirotani, M. (2009). Synchronous versus asynchronous CMC and transfer to Japanese oral performance. Calico Journal, 26(2), 413-438. https://doi.org/10.1016/j.cpen.2012.02.001.

Hismanoglu, M., \& Hismanoglu, S. (2011). Task-based language teaching: What every EFL teacher should do. Procedia Social and Behavioral Sciences, 15, 46-52. https://doi.org/10.1016/j.sbspro.2011.03.049.

Jalilzadeh, K., \& Tahmasebi, A. (2014). Content-based syllabus. European Scientific Journal, 1(September), 223-231.

Jepson, K. (2005). Conversations-And negotiated interaction - In text and voice chat rooms. Language Learning \& Technology, 9(3), 79-98 Retrieved from http://www.lltjournal.org/item/2520.

Kartchava, E., \& Ammar, A. (2014). The noticeability and effectiveness of corrective feedback in relation to target type. Language Teaching Research, 18(4), 428-452. https://doi.org/10.1177/1362168813519373.

Klapper, J. (2003). Taking communication to task? A critical review of recent trends in language teaching. Language Learning Journal, 27(1), 33-42.

Lee, L. (2011). Blogging: Promoting learner autonomy and intercultural competence through study abroad. Language Learning \& Technology, 15(3, SI), 87-109.

Lyster, R. (2001). Negotiation of form, recasts, and explicit correction in relation to error types and learner repair in immersion classrooms. Language Learning, 51(1), 265-301. https://doi.org/10.1111/1467-9922.00039.

Lyster, R., \& Ranta, L. (1997). CORRECTIVE FEEDBACK AND LEARNER UPTAKE: Negotiation of form in communicative classrooms. Studies in Second Language Acquisition, 19(1), 37-66 Retrieved from http://digitool.library.mcgill.ca/R/ ?func=dbin-jump-full\&object_id=19364\&local_base=GEN01-MCG02.

Monteiro, K. (2014). An experimental study of corrective feedback during video-conferencing. Language Learning \& Technology, 18(3), 56-79 Retrieved from http://www.lltjournal.org/item/2870.

Nassaji, H. (2007). Elicitation and reformulation and their relationship with learner repair in dyadic interaction. Language Learning, 57(4), 511-548. https://doi.org/10.1111/j.1467-9922.2007.00427.x.

Oztok, M., Zingaro, D., Brett, C., \& Hewitt, J. (2013). Exploring asynchronous and synchronous tool use in online courses. Computers \& Education, 60(1), 87-94. https://doi.org/10.1016/j.compedu.2012.08.007.

Paechter, M., \& Maier, B. (2010). Online or face-to-face? Students' experiences and preferences in e-learning. The Internet and Higher Education, 13(4), 292-297. https://doi.org/10.1016/j.iheduc.2010.09.004.

Peters, V. L., \& Hewitt, J. (2010). An investigation of student practices in asynchronous computer conferencing courses. Computers \& Education, 54(4), 951-961. https://doi.org/10.1016/j.compedu.2009.09.030.

Rolin-lanziti, J. (2010). The organization of delayed second language correction. Language Teaching Research, 14(2), 183206. https://doi.org/10.1177/1362168809353874

Rosell-Aguilar, F. (2005). Task design for audiographic conferencing: Promoting beginner oral interaction in distance language learning. Computer Assisted Language Learning, 18(5), 417-442. https://doi.org/10.1080/ 09588220500442772.

Sagarra, N., \& Abbuhl, R. (2013). Optimizing the noticing of recasts via computer-delivered feedback: Evidence that oral input enhancement and working memory help second language learning. Modern Language Journal, 97(1), 196216. https://doi.org/10.1111/j.1540-4781.2013.01427.x.

Sarandi, H. (2016). Oral corrective feedback: A question of classification and application. TESQ TESOL Quarterly, 50(1), 235-246. https://doi.org/10.1002/tesq.285.

Sauro, S. (2009). Computer-mediated corrective feedback and the development of L2 grammar. Language, Learning \& Technology, 13(1), 96-120. Retrieved from http://www.lltjournal.org/item/2656.

Sheen, Y. (2006). Exploring the relationship between characteristics of recasts and learner uptake. Language Teaching Research, 4, 361-392. https://doi.org/10.1191/1362168806/r203oa.

Spada, N., \& Frohlich, M. (1995). COLT - communicative orientation of language teaching observation Scheme: Coding conventions and applications. Sydney: National Centre for English Language Teaching and Research.

Van Maele, J., Baten, L., Beaven, A., \& Rajagopal, K. (2013). E-assessment for learning: Gaining insight in language learning with online assessment environments. Computer-assisted foreign language teaching and learning: Technological advances, (pp. 245-261). https://doi.org/10.4018/978-1-4666-2821-2.ch014.

Willis, J. R. (1996). A framework for task-based learning. Harlow, Essex: Longman.

Yang, Y.-T. C., Chuang, Y.-C., Li, L.-Y., \& Tseng, S.-S. (2013). A blended learning environment for individualized English listening and speaking integrating critical thinking. Computers \& Education, 63, 285-305. https://doi.org/10.1016/j. compedu.2012.12.012.

Yilmaz, Y. (2011). Task effects on focus on form in synchronous computer-mediated communication. Modern Language Journal, 95(1), 115-132. https://doi.org/10.1111/j.1540-4781.2010.01143.x. 